\title{
Developing case-mix standards with the Diagnosis-related Groups for payment reforms and hospital management in China: A case study in Xiamen city
}

\author{
Yanbing Zeng ${ }^{1,2}$, Alex Jingwei He ${ }^{3}$, Peng $\mathrm{Lin}^{4}$, Zhonghai Sun ${ }^{5}$, Ya Fang ${ }^{* 1,2}$ \\ ${ }^{1}$ Key Laboratory of Health Technology Assessment of Fujian Province, School of Public Health, Xiamen University, Xiamen, \\ Fujian, China \\ ${ }^{2}$ State Key Laboratory of Molecular Vaccinology and Molecular Diagnostics, School of Public Health, Xiamen University, \\ Xiamen, Fujian, China \\ ${ }^{3}$ Department of Asian and Policy Studies, the Hong Kong Institute of Education, Tai Po, New Territories, Hong Kong, China \\ ${ }^{4}$ School of Economics, Xiamen University, Xiamen, Fujian, China \\ ${ }^{5}$ Xiamen Medical Research Institute, Xiamen, Fujian, China
}

Received: November 18, 2015

Accepted: January 5, 2016

Online Published: January 16, 2016

DOI: $10.5430 /$ ijh.v2n1p102

URL: http://dx.doi.org/10.5430/ijh.v2n1p102

\begin{abstract}
Objective: To inform health insurance payment reforms and hospital cost management by investigating the case-mix of viral hepatitis, a common disease, in a Chinese city.

Methods: All inpatient medical records of viral hepatitis of selected hospitals in Xiamen from 2008 to 2013 were collected. Both univariate and multivariate analyses were performed to test the association between hospitalization costs and other key variables. The CHAID model was employed to generate the Diagnosis-related Groups (DRGS). Evaluation indexes were adopted to evaluate the grouped results. Standard expenditures were estimated for each group.

Results: Gender, age, marital status, mode of payment, admission condition, discharged condition and length of stay were found significantly associated with inpatient expenditures, with $p$ values smaller than .001 . Eleven diagnosis-related groups were obtained with the CHAID methods and three classification nodes were obtained from the CHAID decision tree, including age, admission status and mode of payment. The analysis revealed a considerable discrepancy in expenditures across groups with similar characteristics. This variance suggests the existence of inflated inpatient costs as well as inefficient use of medical resources.

Conclusions: The analysis provided more accurate estimation on case-mix costs for a major disease in China. The standard expenditures are of reference values for the social insurance administration in calibrating reimbursement rates in its move to case-mix payment system and helpful for hospital cost management.
\end{abstract}

Key Words: Diagnosis-related groups, Case-mix, Payment reform, Hospital management, Health policy

*Correspondence: Ya Fang; Email: fangya@xmu.edu.cn; Address: School of Public Health, Xiamen University, Xiang'an Campus, Xiamen City, Fujian Province 361102, China. 


\section{INTRODUCTION}

Health policymakers all over the world are grappling with rising health care expenditure and demand for continuous quality improvement. One of the most prominent tools to emerge in the past two decades is a payment reform that is envisaged as a key "control knob" in health care reforms. There has been a voluminous body of literature of both theoretical modeling and empirical examination on various provider payment mechanisms. Tradeoff effects have been found amongst cost containment, quality of care, quantity of supply, and difficulty of administration. ${ }^{[1,2]}$ In the global escalation of health care costs, there has been broad agreement on the advantages of capitation, case payment, and global budget in paying providers. A proliferation of empirical evidence in East Asia has also demonstrated remarkable changes in cost control and quality maintenance, following the shift to more scientific payment methods. ${ }^{[3-5]}$

The Diagnosis-related Groups (DRGs), a major case payment system that classifies the types of patient treated by diagnosis and relates the case-mix to the associated cost and expenditure, has gained increasing prominence as a means of reimbursing acute inpatient care in many high-income countries. ${ }^{[6]}$ Cross-country empirical investigations reveal that DRGs have in general helped these countries increase hospital efficiency by reducing the average length of stay (LOS) and inpatient costs. ${ }^{[7]}$ Recent years have seen the gradual introduction of DRGs to middle- and low-income countries, largely in response to the mandate of cost control and efficiency improvement. A worldwide survey found that by the end of 2012, twelve low- and middle-income countries had established a DRG-based payment system, while another seventeen countries were piloting or exploring design options for the establishment of such a system. ${ }^{[7]}$

China is in the midst of carrying out an ambitious national health care reform program. Begun in 2009, this landmark reform strives to revamp the country's heavily deteriorated health system by increasing financial accessibility for all and improving quality of service. ${ }^{[8]}$ The implementation of a case-based system has been a key policy priority. A number of local pilots have been launched in developed cities including Beijing, Shanghai, and Chengdu. The design of the DRG system is, however, a rather sophisticated endeavor given the vast amount of data and the technical difficulties involved The most daunting challenge is the design of a comprehensive DRG framework appropriate to the national context. At present, the major variants include the AR-DRG of Australia, CMGs of Canada, and British HRGs, all of which originated more or less from the US-based DRG system. ${ }^{[9]}$ Proper adaptation is of the utmost importance in developing countries because the cost structure of delivery care varies

Published by Sciedu Press considerably more than that in high-income countries, given the lower level of technologies and labor applied. ${ }^{[7]}$

At present, both ICD-9 (the International Classification of Diseases) and ICD-10 diagnosis and procedure codes are used in China. Some local scholars have developed the CADRG132 (the China Adjusted DRG132) based on the ICD-9. As part of the efforts to develop a Chinese grouper suitable for the local context, foreign DRG variants have been tested locally. For instance, Huang analyzed the feasibility of applying the AP-DRG (All Patient DRG) to hospitals in Beijing and reported a coefficient of variation (CV) of $95 \%$ in medical DRGs and $73 \%$ in surgery. The CV for costs was $129 \%$ in medical DRGs and $94 \%$ in surgery. ${ }^{[10]}$ The study of Gong et al. conducted in Chengdu examined the applicability of the Australian AR-DRG and found satisfactory reduction in variance as well as the coefficient of variation. ${ }^{[11]}$ Beijing has made more impressive progress, developing its own Beijing Diagnosis-related Groups (BJ-DRGs). The study by Jian et al. evaluated the performance of BJ-DRGs, AP-DRGs, and AR-DRGs with inpatient data from Beijing. The CV and RIV (reduction in variance) analysis found that the BJDRGs produced the best results in terms of expenditure but performed poorly in others categories. ${ }^{[12]}$

While the development of the Chinese DRG variant has made remarkable progress, it is also necessary to design related DRG-based payment systems. Many past studies evaluating the pilot payment schemes have reported positive effects, mainly in reducing LOS and curbing costs. ${ }^{[13-15]}$ Behind the impressive outcomes, however, lie a variety of unintended consequences associated with the DRG payment mechanisms. For instance, Zhang's study in Shanghai, using different-in-difference strategies, discovered several opportunistic behaviors of hospitals intended to safeguard profits. Specifically, it was found that hospitals were reducing the LOS on patients with target diseases but not reducing outlays. More importantly, hospitals were found engaging in cost-shifting strategies by which they raised outlays on uninsured patients to compensate for reduced revenues on insured patients. ${ }^{[15]}$ This tells scholars and policymakers that the implementation of scientific payment arrangements may not necessarily lead to immediate cost relief for all patients. An effective DRG-based payment reform must proceed with appropriately aligned incentives and accurate estimation of medical outputs and costs.

This article illuminates the construction of a case-mix payment system in China by estimating the reference value of hospitalization expenditure for a common disease based on DRG grouping. We collected inpatient records of viral hepatitis in four major tertiary hospitals in Xiamen City, China 
and used the CHAID method (Chi-squared Automatic Interaction Detection) to establish case-mix groups based on expenditure and other related factors. The standard expenditure and its range for each group were then estimated to provide points of reference for social health insurance in setting reimbursement standards and for hospitals in managing medical resources.

\section{MATERiAl AND METHODS}

\subsection{Study field}

This study takes patients with viral hepatitis in Xiamen City as the unit of analysis. Located on the Southeast coast of mainland China, Xiamen is a medium-sized city with a population of 3.7 million. ${ }^{[16]}$ Health facilities include 36 hospitals, 13 township health centers, and 25 community health centers providing 10,769 beds and staffed by 17,829 health professionals. ${ }^{[25]}$ Social health insurance schemes now almost cover the entire population without discriminating against migrant workers. In 2010, the central government chose Xiamen as one of the key pilot cities for the public hospital reforms. The wide coverage of social health insurance has enabled the government to undertake major reforms of both the financing and provision of health services. The DRG-based payment reform was introduced against this backdrop.

\subsection{Analytical steps}

The analysis of this study was organized as follows. First, the rank-sum test and multiple linear regression analysis were employed to detect the factors associated with inpatient costs for the virus hepatitis. Second, we established a DRG model using the CHAID method and adopted evaluation indices to evaluate the grouped results, including RIV and CV. In the final step, we analyzed the patterns of medical expenditures in treating hepatitis. Outlier expenses were also scrutinized to identify the association of factors based on case-mix analysis. The results generated are of value for hospitals to accurately estimate medical outputs and for social insurers to set reasonable reimbursement criteria for the selected disease.

\subsection{Data source}

The data for this study came from the medical record archives of four comprehensive tertiary hospitals in Xiamen. According to official statistics, they provide 6,203 hospital beds $(57.6 \%)$ in the city and attend to $80 \%$ of patients with viral hepatitis. ${ }^{[17]}$ We collected the records of all patients who had been diagnosed with viral hepatitis, hospitalized, and discharged from 2008 to 2013. All information linked to personal identity was removed to safeguard privacy. Viral hepatitis was chosen as it is not only a common disease but also particularly prevalent in China. ${ }^{[18]}$ Most diseases are treated on a fee-for-service basis in Xiamen, and the social health insurance administration is now planning to move to alternative provider payment systems for major common diseases, including hepatitis.

Two well-trained research assistants collected data from the archives, with ethical approval from the authors' research institutions and permission from the hospital. A total of 14,408 cases were collected, of which 7,095 were excluded due to missing values, logical errors, or the label "uncured". Ultimately, an effective sample of 7,313 inpatient cases was formed. The dataset contained three groups of variables. The first group was demographic and financial variables, including gender, age group ( $\leq 15,16-39,40-55$, or $>55)$, marital status (single, married, divorced, or widowed), and mode of payment (out-of-pocket, social health insurance, private commercial insurance, or government medical benefits). The second group of variables was related to inpatient details, including admission condition (general or emergency), operation status (yes or no), and discharged condition (cured or improved). The third group included LOS and total inpatient costs. When cleaning up the data, a few sparsely populated values were merged with others in the interest of simplicity. Specifically, there were only two divorced cases and one widow; both were merged into the "single" category. In addition, there were only four individuals with commercial insurance and five with government medical benefits. We created a new category called "medical insurance" to include all types of insurance.

\subsection{Statistical methods}

Descriptive statistics were used to summarize the characteristics of the hospitalization expenditure. Univariate analysis and multivariate regression were performed to detect the correlation between expenditures and other variables. Statistical significance was defined as a $p$ value of .1 or lower.

CHAID algorithm was applied in SPSS 17.0 to establish case-mix groups based on expenditure and other related variables. CHAID is a decision tree technique commonly used for the prediction, classification, and detection of interaction between variables. ${ }^{[19]}$ In the CHAID analysis, the first step was to create categorical predictors and then to determine a pair of categories for each one. In the next step, we chose the split of the predictor variable with the smallest adjusted $p$-value, i.e., the predictor variable that yielded the most significant split; if the smallest adjusted $\mathrm{p}$-value for any predictor was greater than the alpha-to-split value, no further splits would be performed, and then the respective node became a terminal node. The procedure continued until no other splits were significant. ${ }^{[20]}$

\subsection{Evaluation index}

RIV was used to measure the reduction in variation in the dependent variable achieved by the classification, which re- 
flected DRGs' predictive validity. High RIV predicted a rigorous classification system. Simultaneously, CV was used to measure the within-group homogeneity of DRGs. Distributions with $\mathrm{CV}<1$ were considered low-variance, whereas those with $\mathrm{CV}>1$ were considered high-variance. Low CV predicted a rigorous classification system. ${ }^{[21]}$

\section{Results}

\subsection{Univariate analysis}

The description of key variables is presented in Table 1. Approximately three-quarters of the patients $(73.95 \%)$ in the sample were male. Most patients were aged between 16 and $39(70.57 \%)$ and reported a married status $(72.45 \%)$.
Roughly three-quarters $(74.66 \%)$ were covered by medical insurance that entailed varying degrees of copayment. Almost all (99.93\%) did not undergo operations, and hence this variable was omitted from the multivariate regression.

The Mann-Whitney U test and the Kruskal-Wallis $\mathrm{H}$ test were performed to compare the medical expenditures stratified by gender, age group, marital status, mode of payment, admission condition, operation status, and discharged condition. Differences among all variables mentioned above were statistically significant, with $p$ values smaller than .001 . The Spearman's Rank Correlation analysis indicated that expenditure was positively correlated with LOS (correlation coefficient $=0.379 ; p$ value $<.001)$.

Table 1. Inpatient characteristics and expenditures sorted by key variables $(\mathrm{N}=7,313)$ (Source: the authors)

\begin{tabular}{|c|c|c|c|c|c|c|}
\hline \multirow{2}{*}{ Characteristic } & \multirow{2}{*}{$N(\%)$} & \multicolumn{3}{|c|}{ Expenditure } & \multirow{2}{*}{ Statistics } & \multirow{2}{*}{$p$ values } \\
\hline & & Median & Lower quartile & Upper quartile & & \\
\hline \multicolumn{7}{|l|}{ Individual-level factors } \\
\hline \multicolumn{7}{|l|}{ Gender } \\
\hline Male & $5,408(73.95)$ & $6,772.44$ & $4,051.97$ & $9,422.30$ & \multirow{2}{*}{-4.261} & \multirow{2}{*}{$<.001$} \\
\hline Female & $1,905(26.05)$ & $6,216.74$ & $3,789.17$ & $8,794.27$ & & \\
\hline Age (years) & & $4,422.11$ & $2,472.43$ & $7,496.24$ & \multirow{5}{*}{$155.239^{*}$} & \multirow{5}{*}{$<.001$} \\
\hline$\leq 15$ & $137(1.87)$ & $6,393.33$ & $3,902.34$ & $8,696.11$ & & \\
\hline $16-39$ & $5,168(70.67)$ & $7,401.83$ & $4,387.19$ & $10,574.03$ & & \\
\hline $40-55$ & $1,541(21.07)$ & $7,889.09$ & $4,558.48$ & $13,385.14$ & & \\
\hline$>55$ & $467(6.39)$ & $5,843.47$ & $3,636.68$ & $8,327.00$ & & \\
\hline \multicolumn{2}{|l|}{ Marital status } & $6,943.05$ & $4,194.18$ & $9,575.83$ & \multirow{3}{*}{-8.533} & \multirow{3}{*}{$<.001$} \\
\hline Single & $2,015(27.55)$ & $5,860.91$ & $3,546.39$ & $9,004.08$ & & \\
\hline Married & $5,298(72.45)$ & $6,890.29$ & $4,143.59$ & $9,317.91$ & & \\
\hline \multicolumn{2}{|l|}{ Mode of payment } & $6,065.30$ & $3,644.84$ & $8,525.79$ & \multirow{3}{*}{-6.069} & \multirow{3}{*}{$<.001$} \\
\hline OOP & $1,853(25.34)$ & $7,171.03$ & $4,470.16$ & $10,060.01$ & & \\
\hline Insured & $5,460(74.66)$ & $6,603.83$ & $3,998.20$ & $9,261.04$ & & \\
\hline \multicolumn{2}{|l|}{ Clinical-level factors } & $3,374.19$ & $1,757.14$ & $8,153.94$ & & \\
\hline \multicolumn{2}{|l|}{ Admission condition } & $6,365.91$ & $3,865.76$ & $8,563.44$ & \multirow{3}{*}{-11.150} & \multirow{3}{*}{$<.001$} \\
\hline General & $3,704(50.65)$ & $6,738.50$ & $4,069.74$ & $9,710.32$ & & \\
\hline Emergency & $3,609(49.35)$ & $6,772.44$ & $4,051.97$ & $9,422.30$ & & \\
\hline \multicolumn{2}{|l|}{ Operation status } & $6,216.74$ & $3,789.17$ & $8,794.27$ & \multirow{3}{*}{-1.440} & \multirow{3}{*}{.150} \\
\hline No & $7,308(99.93)$ & $4,422.11$ & $2,472.43$ & $7,496.24$ & & \\
\hline Yes & $5(0.07)$ & $6,393.33$ & $3,902.34$ & $8,696.11$ & & \\
\hline \multicolumn{2}{|l|}{ Discharged status } & $7,401.83$ & $4,387.19$ & $10,574.03$ & \multirow{3}{*}{-4.930} & \multirow{3}{*}{$<.001$} \\
\hline Cured & $2,502(34.2)$ & $7,889.09$ & $4,558.48$ & $13,385.14$ & & \\
\hline Improved & $4,811(65.8)$ & $5,843.47$ & $3,636.68$ & $8,327.00$ & & \\
\hline
\end{tabular}

Note. ${ }^{*}$ Age: Kruskal-Wallis H test; other factors: Mann-Whitney U test

\subsection{Multiple regression analysis}

Prior to the multiple regression analysis, normality tests for expenditure and LOS were performed using the Kolmogorov-
Smirnov Test. When we took the logarithm of expenditure, the $p$ value was .098 , indicating the acceptance of the normal distribution hypothesis. Table 2 displays the results of the 
multiple regression analysis in which the logarithm of expenditure was the dependent variable while gender, age, marital status, mode of payment, admission condition, discharged condition, and LOS were independent variables. As illustrated in Table 2, gender, age, marital status, mode of payment, admission condition, and discharged condition were all significantly associated with the logarithm of expenditure. Moreover, the table suggests that when other variables were controlled, patients with viral hepatitis aged over 55 had the highest expenditure, followed by those aged between 40 and 55, then those between 16 and 39, and younger than 15, respectively. The analysis also shows that the insured paid more than fee-paying patients and that emergency-admitted patients paid higher fees than those treated via general admission.

Table 2. Multiple regression analyses on the association between expenditure and other key variables (Source: the authors)

\begin{tabular}{|c|c|c|c|c|c|}
\hline Factor & Coefficient & Standard deviation & Standardized coefficient & $\mathbf{T}$ & $p$ value \\
\hline Constant & $-4,742.447$ & $2,864.595$ & & -1.656 & .098 \\
\hline Gender & -394.117 & 169.484 & -0.024 & -2.325 & .020 \\
\hline Age & 866.315 & 179.239 & 0.054 & 4.833 & $<.001$ \\
\hline Marital status & $1,863.991$ & 129.388 & 0.162 & 14.406 & $<.001$ \\
\hline Mode of payment & -693.77 & 178.514 & -0.042 & -3.886 & $<.001$ \\
\hline Admission condition & $1,434.684$ & 149.677 & 0.101 & 9.585 & $<.001$ \\
\hline Discharge status & $1,652.943$ & 158.878 & 0.11 & 10.404 & $<.001$ \\
\hline LOS & 200.146 & 5.179 & 0.419 & 38.647 & $<.001$ \\
\hline
\end{tabular}

\subsection{DRGs and standards of expenditure}

The variables significantly correlated with the dependent variable (expenditure) were entered into the CHAID model as predictors. In the process of variable selection, we had also considered an appropriate number of classification nodes and the stop conditions for tree growth, both of which were crucial in generating a classification tree in the CHAID analysis.
If the number of nodes was too small, patients with different characteristics could not be well classified, resulting in great variance of medical expenditure within groups. On the other hand, if the number of nodes was too large, the classification tree would become too big to fit the data, causing considerable inconvenience in reimbursement practices in the future.

Table 3. Expenditures for DRGs groups and reference values for reimbursement (CNY) (Source: the authors)

\begin{tabular}{lllllll}
\hline Node & Group & Standard expenditure & Upper bound & Median & Inter-quartile range & $\mathbf{C V}^{*}$ \\
\hline 1 & $\leq 15$ & $4,387.55$ & $15,031.94$ & $4,422.11$ & $5,023.81$ & 0.83 \\
8 & $40-55$, emergency & $7,477.91$ & $21,984.34$ & $7,877.17$ & $6,729.66$ & 0.94 \\
10 & $>$ 55, emergency & $7,665.11$ & $27,769.58$ & $7,977.53$ & $9,364.70$ & 0.90 \\
11 & 16-39, general, OOP & $4,756.75$ & $14,070.41$ & $4,895.93$ & $4,401.18$ & 0.80 \\
12 & 16-39 general, insured & $5,861.03$ & $15,128.80$ & $6,111.71$ & $4,608.26$ & 1.02 \\
13 & 16-39, emergency, OOP & $5,647.59$ & $16,326.23$ & $5,969.30$ & $5,025.36$ & 0.84 \\
14 & 16-39, emergency, insured & $7,129.33$ & $16,975.56$ & $7,324.03$ & $4,918.46$ & 0.73 \\
15 & $40-55$, general, OOP & $5,563.06$ & $16,726.40$ & $5,641.62$ & $5,215.88$ & 0.70 \\
16 & $40-55$, general, insured & $6,578.50$ & $18,635.40$ & $7,022.84$ & $5,854.70$ & 0.99 \\
17 & $>55$, general, OOP & $6,887.33$ & $21,781.65$ & $7,045.95$ & $7,079.82$ & 0.76 \\
18 & $>55$, general, insured & $7,974.45$ & $26,499.97$ & $8,710.68$ & $8,583.89$ & 0.76 \\
\hline
\end{tabular}

Note. ${ }^{*} \mathrm{CV}$ : Coefficient of Variation is defined as the ratio of the standard deviation $\sigma$ to the mean $\mu$

Figure 1 presents the CHAID analysis tree. We used age, admission status, and mode of payment as first, second, and third classification nodes respectively. A series of groups with common characteristics was formed accordingly. Table 3 presents the median, interquartile range (IQR), and upper bound of expenditure for each group (upper bound = upper quartile + 1.5 IQR).

To calculate the standard of expenditure, we eliminated extreme expenditures higher than the upper bound, and calculated the medians of the expenditures. Such standards are of reference value for social health insurers in setting 
reimbursement rates. The standard expenditure for insured patients above 55 via general admission was 7,974.45 CNY, the highest amongst all groups, while that of patients aged 15 or below was the lowest $(4,387.55 \mathrm{CNY})$. Overall, the standards were higher for the insured groups than those of out-of-

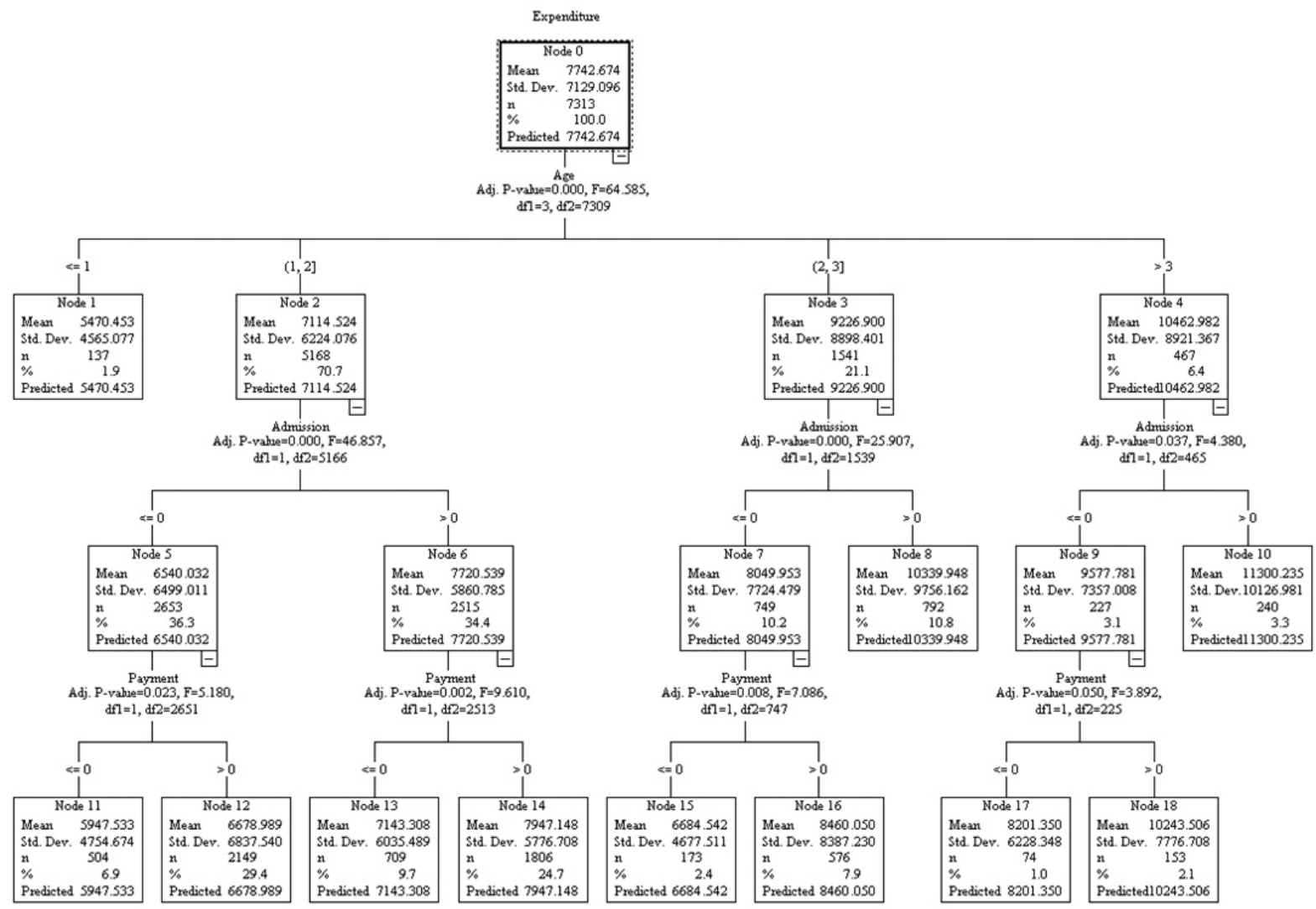

Figure 1. Case classification tree

\subsection{DRG evaluation}

We performed the Kruskal-Wallis $\mathrm{H}$ test to compare the differences in expenditure among the three diagnosis-related groups. The results yielded $(\mathrm{H}=345.78 ; p<.001)$ indicated statistically significant heterogeneity amongst groups. RIV was also tested and we obtained a value of $23.88 \%$, suggesting satisfactory performance of classification. CV was employed to assess the homogeneity of individual DRGs. As shown in Table 3, the CV values yielded reflected high homogeneity $(\mathrm{CV} 1=0.83, \mathrm{CV} 8=0.94, \mathrm{CV} 10=0.90, \mathrm{CV} 11$ $=0.80, \mathrm{CV} 12=1.02, \mathrm{CV} 13=0.84, \mathrm{CV} 14=0.73, \mathrm{CV} 15=$ $0.70, \mathrm{CV} 16=0.99, \mathrm{CV} 17=0.76, \mathrm{CV} 18=0.76$ ).

To fulfill the second research objective of this study, we looked to determine the number and percentage of high-cost patients and their patterns of medical resource consumption. We then analyzed the percentage of expenditures as well as the percentage of patients whose expenditures exceeded the standard value in each node. As Table 4 shows, in Node 1, pocket payment. For instance, in Node 12 (16-39 years old, insured, general admission), the expenditure was 5,861.03 CNY, whereas in Node 11 (age 16-39, out-of-pocket, general admission), the expenditure was only 4,756.75 CNY. for instance, while $1.46 \%$ of patients had seen their expenditures exceed the standard, they had consumed $7.77 \%$ of the total expenditures, revealing a considerable discrepancy in resource utilization. Similar patterns were also found in most other groups. On average, while the medical expenditure of $4.87 \%$ of all patients in the sample went beyond the standard rate, they consumed $17.71 \%$ of total expenditures. Thus we found a skewed distribution of resource consumption, with the "high-cost" $5 \%$ consuming a quarter of the resources consumed by the "low-cost" $95 \%$.

\section{Discussion AND CONCLUSION}

In this study, we analyzed systematic secondary data on treating the hepatitis virus in four major tertiary hospitals in Xiamen City, China and attempted to achieve two research purposes. First, we sought to illuminate the construction of a case-based payment system for the ongoing provider payment reforms using the case of a common disease. Sec- 
ond, we intended to disentangle the cost structure across groups of patients with similar characteristics and to help hospital managers identify the potential leakages in resource utilization.

We first identified major independent variables including gender, age, marital status, mode of payment, admission condition, and discharged status that had been found to be significantly associated with medical expenditures, the dependent variable. This result was in line with literatures. ${ }^{[22-25]} \mathrm{We}$ then applied the CHAID technique to classify all inpatients into homogeneous groups while minimizing the variance of expenditures within each group. All classification nodes used in the CHAID analysis were important variables affecting medical expenditures of patients with viral hepatitis. Age, mode of payment, and admission status were employed as classification indices in the CHAID algorithm.

Table 4. Percentage of patients with costs exceeding the threshold and percentage of costs (Source: the authors)

\begin{tabular}{lll}
\hline Node & \% of expenditures exceeding upper bound & \% of patients whose expenditures exceeded upper bound \\
\hline 1 & 7.77 & 1.46 \\
8 & 28.84 & 8.71 \\
10 & 26.90 & 7.92 \\
11 & 15.34 & 4.17 \\
12 & 14.28 & 4.14 \\
13 & 19.08 & 5.36 \\
14 & 13.02 & 3.93 \\
15 & 9.12 & 2.31 \\
16 & 23.02 & 5.90 \\
17 & 14.66 & 4.05 \\
18 & 13.83 & 3.92 \\
All & 17.71 & 4.87 \\
\hline
\end{tabular}

We estimated the standard of medical expenditures for inpatients with viral hepatitis by employing the classification developed. The analysis provided more accurate estimation of case-mix costs for a major disease in Xiamen. The standard expenditures derived are of value as references for the social insurance administration to calibrate reimbursement arrangements in its move to the case-mix payment system. Furthermore, we have estimated the upper bound for each group obtained by DRGs, based on which hospitals could set more accurate guidelines for medical resource consumption. In this study, the expenditures of more than $5 \%$ of patients exceeded the upper bounds in all groups, indicating that a few patients have cost disproportionately more resources, with other variables controlled. This has provided additional evidence for insurance-induced demands and other inefficient uses of resources. A previous study evaluated cost outliers in a Belgian hospital and their results showed $6.3 \%$ of high resource use outliers and $1.1 \%$ for low resource use outliers. ${ }^{\text {[26] }}$ Some investigators believed that the early intervention in the DRG introduction process was partially successful because of improvement of the calculation standards, advancements in hospitals' cost accounting, and evaluation studies and recommendations concerning the DRG assignment. ${ }^{[27]}$ DRGs could be used as a tool to facilitate more effective resource planning and cost management in hospitals. The methods used in this study could also be applied to other major dis- eases.

This study makes two contributions. First, though the wellintended goal of China's health care reform is to reduce the heavy financial burden on citizens, social health insurance covering close to $100 \%$ of the population has yet to have a significant impact, especially in mitigating the out-of-pocket burden caused by catastrophic diseases. ${ }^{[28,29]}$ This is in part attributable to various flawed arrangements within the insurance system, such as inappropriately set reimbursement ceilings and copayment rates, as well as the limited capacity of social insurance administration. ${ }^{[30,31]}$ Among others things, the recalibration of reimbursement standards, especially for common diseases, is of critical importance in local insurance payment reforms.

Second, despite the scarcity of medical resources, there is huge waste in the Chinese health care system. ${ }^{[32]}$ A multitude of misaligned incentives has driven hospital staff toward overprescribing drugs, abusing high-tech diagnostic tests, and making inefficient uses of other resources. ${ }^{[33,34]}$ Identifying and repairing the leakages are of long-term critical significance for health planning and hospital management; this is one of the core concerns for government, health insurance administration, and hospitals. DRGs have the potential to act as a useful tool for this purpose. ${ }^{[35]}$ This study provides fresh evidence for health care providers to estimate the outputs 
and costs associated with specific common diseases.

We must acknowledge the limitations of this study. First, as only one disease was chosen, the results may not necessarily fit the distribution of hospitalization costs for other diseases. Second, the sheer size of China's territory and population frustrate the generalization efforts of virtually all case studies. However, it is not the intention of the authors to generalize the findings to China as a whole. This study presents an initial effort using advanced techniques such as the CHAID method for rigorous quantitative analysis of the application of case-mix systems in China. Further studies will be conducted in the future, including more diseases and expanding to other regions, to illuminate further China's health care reforms.

\section{ACKNOWLEDGEMENTS}

This study was funded by the National Natural Sciences Foundation of China (Ref. 71403229), the Natural Sciences Foundation of Fujian Province (Ref. 2013J05108), and the Early Career Scheme of the Research Grants Council of Hong Kong Special Administrative Region Government (Ref. 859213). The funding bodies had no role in the study.

\section{CONFlicts OF InTEREST Disclosure}

The authors delare no conflicts of interest.

\section{REFERENCES}

[1] Ellis RP, McGuire TG. Provider behavior under prospective reimbursement: cost sharing and supply. Journal of Health Economics. 1986; 5: 129-51. http://dx.doi.org/10.1016/0167-6296(86 ) $90002-0$

[2] Barnum H, Kutzin J, Saxenian H. Incentives and provider payment methods. International Journal of Health Planning and Management. 1995; 10: 23-45. PMID:10142120. http://dx.doi .org/10.1002 /hpm. 4740100104

[3] Eggleston K, Hsieh CR. Healthcare payment incentives: a comparative analysis of reforms in Taiwan, South Korea and China. Applied Health Economics and Health Policy. 2004; 3: 4756. PMID:15702940. http://dx.doi.org/10.2165/0014836 5-200403010-00009

[4] Yip W, Eggleston K. Provider payment reform in China: the case of hospital reimbursement in Hainan Province. Health Economics. 2001; 10: 325-39. PMID:11400255. http://dx.doi.org/10.10 $02 /$ hec. 602

[5] Yip WK, Eggleston K. Addressing government and market failures with payment incentives: hospital reimbursement reform in Hainan, China. Social Science and Medicine. 2004; 58: 267-77. http://dx.doi.org/10.1016/S0277-9536(03)00010-8

[6] Mathauer I, Wittenbecher F. Hospital payment systems based on diagnosis-related groups: experiences in low- and middle-income countries. Bulletin of the World Health Organization. 2013; 91: 74656. PMID:24115798. http://dx.doi.org/10.2471/BLT.12.11 5931

[7] Street A, O'Reilly J, Ward P, et al. DRG-based hospital payment and efficiency: theory, evidence and challenges. In: Busse R, Geissler A, Quentin W, Wiley M, Eds. Diagnosis-related Groups in Europe: Moving towards Transparency, Efficiency and Quality in Hospitals. Maidenhead: Open University Press; 2011. 93-114 p.

[8] Chen Z. Launch of the health-care reform plan in China. The Lancet. 2009; 373: 1322-4. http://dx.doi.org/10.1016/S0140-673 6(09) 60753-4

[9] Pilla J, Hindle D. Adapting DRGs, the British, Canadian and Australian experiences. Australian Health Information Management. 1994; 24: 87-93. PMID:10141151.

[10] Huang H. Feasibility of applying DRGs in Beijing hospital management. Journal of Chinese Hospital Management. 1994; 10: 131-6.

[11] Gong Z, Duckett SJ, Legge DG, et al. Describing Chinese hospital activity with diagnosis related groups: a case study in Chengdu.
Health Policy. 2004; 69: 93-100. PMID:15484610. http://dx.doi . org/10.1016/j.healthpol.2003.12.004

[12] Jian W, Cui T, Hu M. Evaluating performance of local case-mix system by international comparison: a case study in Beijing, China. International Journal of Health Planning and Management. 2011; 26: 471 81. PMID:22213262. http://dx.doi .org/10.1002/hpm.1111

[13] Wu A, Li YP, Zhang YY, et al. DRG-based payment reform for urban health insurance scheme. Chinese Journal of Health Economics. 2004; 9: 38-9.

[14] Yang Z, Zhao ZY, Liu D. The impact of DRG-based user charge on expenditure control. Chinese Journal of Health Economics. 2001; 4 : 25-6.

[15] Zhang J. The impact of a diagnosis-related group-based prospective payment experiment: the experience of Shanghai. Applied Economics Letters. 2010; 17: 1797-1803. http://dx.doi.org/10. $1080 / 13504850903317347$

[16] Xiamen Municipal Bureau of Statistics. 2013 Statistical Report of Economic and Social Development of Xiamen City. Available from: http://www.stats-xm.gov.cn/tjzl/tjgb/ndgb/2014 03/t20140320_24192.htm(accessedon20/12/2014)

[17] Xiamen Municipal Bureau of Health. 2010 Profile of Health System of Xiamen. Available from: http://xxgk.xm.gov.cn/wsj/ml/04/01/201101/t2011 0110_778930.htm (accessedon20/12/2014)

[18] Antony J, Celine TM. A hospital-based retrospective study on frequency and distribution of viral hepatitis. Journal of Global Infectious Diseases. 2014; 6: 99-104. PMID:25191049. http://dx.doi .org /10.4103/0974-777X.138499

[19] Chaturvedi A, Green PE. Book Review: SPSS for Windows, CHAID6.0. Journal of Marketing Research. 1995; 32: 245-54. http://dx.doi.org/10.2307/3152056

[20] McCartya JA, Hastak M. Segmentation approaches in data-mining: a comparison of RFM, CHAI and logistic regression. Journal of Business Research. 2007; 60: 656-62. http://dx.doi.org/10.1016 /j.jbusres. 2006.06.015

[21] Palmer G, Reid B. Evaluation of the performance of diagnosis-related groups and similar casemix systems: methodological issues. Health Services Management Research. 2001; 14: 71-81. PMID:11373998. http://dx.doi.org/10.1258/0951484011912564

[22] Sedman AB, Bahl V, Bunting E, et al. Clinical Redesign Using All Patient Refined Diagnosis Related Groups. PEDIATRICS. 2004; 114: 
965-969. PMID:15466092. http://dx.doi.org/10.1542/peds . 2004-0650

[23] Taylor DJ, Whellan D, Sloan F. Effects of admission to a teaching hospital on the cost and quality of care for Medicare beneficiaries. The New England Journal of Medicine. 1999; 4: 293 299. PMID:9920955. http://dx.doi.org/10.1056/NEJM199 901283400408

[24] Freitas A, Silva-Costa T, Lopes F, et al. Factors influencing hospital high length of stay outliers. BMC Health Services Research. 2012; 12: 265-275. PMID:22906386. http://dx.doi.org/10.1186/1 472-6963-12-265

[25] He Fan, Shen Y, Liu BY. Case mixes of inpatients in Zhejiang Province. Chinese Journal of Hospital Administration. 2006; 7: 460464.

[26] Pirson M, Dramaix M, Leclercq P, et al. Analysis of cost outliers within APR-DRGs in a Belgian general hospital: Two complementary approaches. Health Policy. 2006; 76: 13-25. PMID:15921818. http://dx.doi.org/10.1016/j.healthpol.2005.04.008

[27] Hensen P, Furstenberg T, Luger TA, et al. Case mix measures and diagnosis-related groups: opportunities and threats for inpatient dermatology. JEADV. 2005; 19: 582-588. http://dx.doi.org/10. $1111 / j .1468-3083.2005 .01258 . x$

[28] Meng Q, Xu L, Zhang YG, et al. Trends in access to health services and financial protection in China between 2003 and 2011: a cross-sectional study. The Lancet. 2012; 379: 805-14. http: //dx.doi.org/10.1016/S0140-6736(12)60278-5
[29] Yang W, Wu X. Paying for outpatient care in rural China: cost escalation under China's New Co-operative Medical Scheme. Health Policy and Planning. 2014. http://dx.doi.org/10.1093/heapol/cz t111

[30] Barber SL, Yao L. Development and status of health insurance systems in China. International Journal of Health Planning and Management. 2014; 26: 339-56. PMID:22095892. http://dx.doi.org/1 $0.1002 / \mathrm{hpm} .1109$

[31] Yan F, Raven J ,Wang W, et al. Management capacity and health insurance: the case of the New Cooperative Medical Scheme in six counties in rural China. International Journal of Health Planning and Management. 2014; 26: 357-78. PMID:20333775. http: //dx.doi.org/10.1002/hpm. 1028

[32] Yip W, Hsiao WC. The Chinese health system at a crossroads. Health Affairs. 2008; 27: 460-8. PMID:18332503. http://dx.doi.org /10.1377/hlthaff .27 .2 .460

[33] Hsiao WC. When incentives and professionalism collide. Health Affairs. 2008; 27: 949-51. PMID:18607027. http://dx.doi.org/1 $0.1377 /$ hlthaff .27 .4 .949

[34] He J. China's ongoing public hospital reform: initiatives, constraints and prospect. Journal of Asian Public Policy. 2011; 4: 342-49. http://dx.doi.org/10.1080/17516234.2011.630228

[35] He J, Yang W. Clinical pathways in China: an evaluation. International Journal of Health Care Quality Assurance. 2015; 28: in press. PMID:25982639. http://dx.doi.org/10.1108/IJHCQA-09-2 014-0096 